\title{
THE RELATIONSHIP BETWEEN CEREBROSPINAL FLUID PRESSURE AND ATHEROGENIC INDEX OF PLASMA IN IDIOPATIC INTRACRANIAL HYPERTENSION PATIENTS
}

\author{
Fatma Şimşek ${ }^{1}$, Recep Yevgi ${ }^{1}$, Yıldız Dağc1 ${ }^{2}$ \\ Correspondence: klamaks@hotmail.com \\ ${ }^{1}$ Ataturk University, Faculty of Medicine, Department of Neurology, Erzurum, Turkey \\ ${ }^{2}$ Erzurum Training and Research Hospital, Department of Neurology, Erzurum, Turkey
}

\begin{abstract}
Article History:
Received: November 24, 2021

Accepted: Desember 15, 2021

Published: January 1, 2022

Cite this as:

Şimşek F, Yevgi R, Dağcl Y. The relationship between

cerebrospinal fluid pressure and atherogenic index of plasma in idiopatic intracranial

hypertension patients. Malang

Neurology Journal; 2022.8:11

15. DOI:

http://dx.doi.org/10.21776/ub.mnj .2022.008.01.3
\end{abstract}

\section{ABSTRACT}

Background: Idiopathic intracranial hypertension (IIH) is a disease thought to be associated with obesity and rapid weight gain. There is no objective parameter with practical use in its follow-up and treatment other than optical coherence tomography.

Objective: The aim of our study is to investigate the relationship between atherogenic index of plasma (AIP) and cerebrospinal fluid (CSF) pressure.

Methods: Serum vitamin B12, vitamin D, homocysteine, folic acid, triglyceride (TG), high density lipoprotein cholesterol (HDL-C) levels, CSF pressure, CSF microprotein levels were recorded from the file data of patients diagnosed with IIH. AIP was calculated by dividing the TG level logarithmically by HDL-C. Height $(\mathrm{kg})$ and weight $(\mathrm{kg})$ data of the patients were used to calculate the body mass index (BMI).

Results: File data of 64 patients were examined. 8 patients with secondary intracranial hypertension were excluded from the study. $80.36 \%$ of the patients were overweight, $16.07 \%$ were obese, $3.57 \%$ were with normal weight. There was no significant correlation between vitamin B12, vitamin D, homocysteine, HDL-C and CSF microprotein levels and CSF pressure level in patients with a diagnosis of IIH. There was a negative correlation between folic acid level and CSF pressure level, and a positive correlation between BMI, TG, AIP and CSF pressure level.

Conclusion: Using folic acid supplements and drugs that reduce TG levels can contribute positively to the course of the disease.

Keywords: Obesity, Atherogenic index of plasma, Folic acid, Cerebrospinal fluid pressure

\section{Introduction}

Idiopathic intracranial hypertension (IIH) is generally defined as a disease of overweight women of childbearing age, characterized by headache, with normal neuroimaging and cerebrospinal fluid (CSF) biochemistry. Pseudotumor cerebri is a broader term that includes both idiopathic and secondary intracranial hypertension reasons. Approximately $70-80 \%$ of IIH patients are obese and more than $90 \%$ are overweight. ${ }^{1-4}$ Clinically, patients have complaints such as headache, nausea, vomiting, visual disturbances, eye pain, pulse-synchronized tinnitus, shoulder and arm pain., 5 Weight loss is considered an effective option in treatment. ${ }^{7}$ Although its etiology is not known clearly, different reasons have been proposed. These include increased CSF production, increased CSF volume due to obstruction in CSF output, increased cerebral arterial pressure, increased cerebral venous pressure causing increased CSF volume and decreased CSF output. ${ }^{8}$

Obesity is one of the reasons that play a role in the etiology of different diseases. There are many studies showing that obesity and blood lipids are closely related. ${ }^{9-11}$ Atherogenic index of plasma (AIP) is a new index of triglycerides (TG) and high density lipoprotein cholesterol (HDL-C) and is calculated by $\log 10$ (TG/HDL-C). ${ }^{12}$ This parameter has been used to measure blood lipid levels and is commonly used as an indicator of dyslipidemia and related diseases. ${ }^{13-}$ 15 A study conducted has proven that AIP has a superior predictive power than conventional lipid profiles for obesity. ${ }^{16}$ AIP can be a parameter that can be used in determining new treatment strategies and disease follow-up in obesity-related diseases. In our study, we aimed to investigate the relationship between CSF pressure and AIP in IIH, which is a disease associated with obesity.

\section{Methods}

\section{Data collection}

The study was carried out in the Neurology Clinic of Erzurum Atatürk University. The data were obtained from the files of patients diagnosed with IIH who were followed in the neurology clinic between October 2015 and December 2019. The information of the patients was accessed through the hospital information system. Local ethics committee approval was obtained for the study (03/01/26.03.2020). 

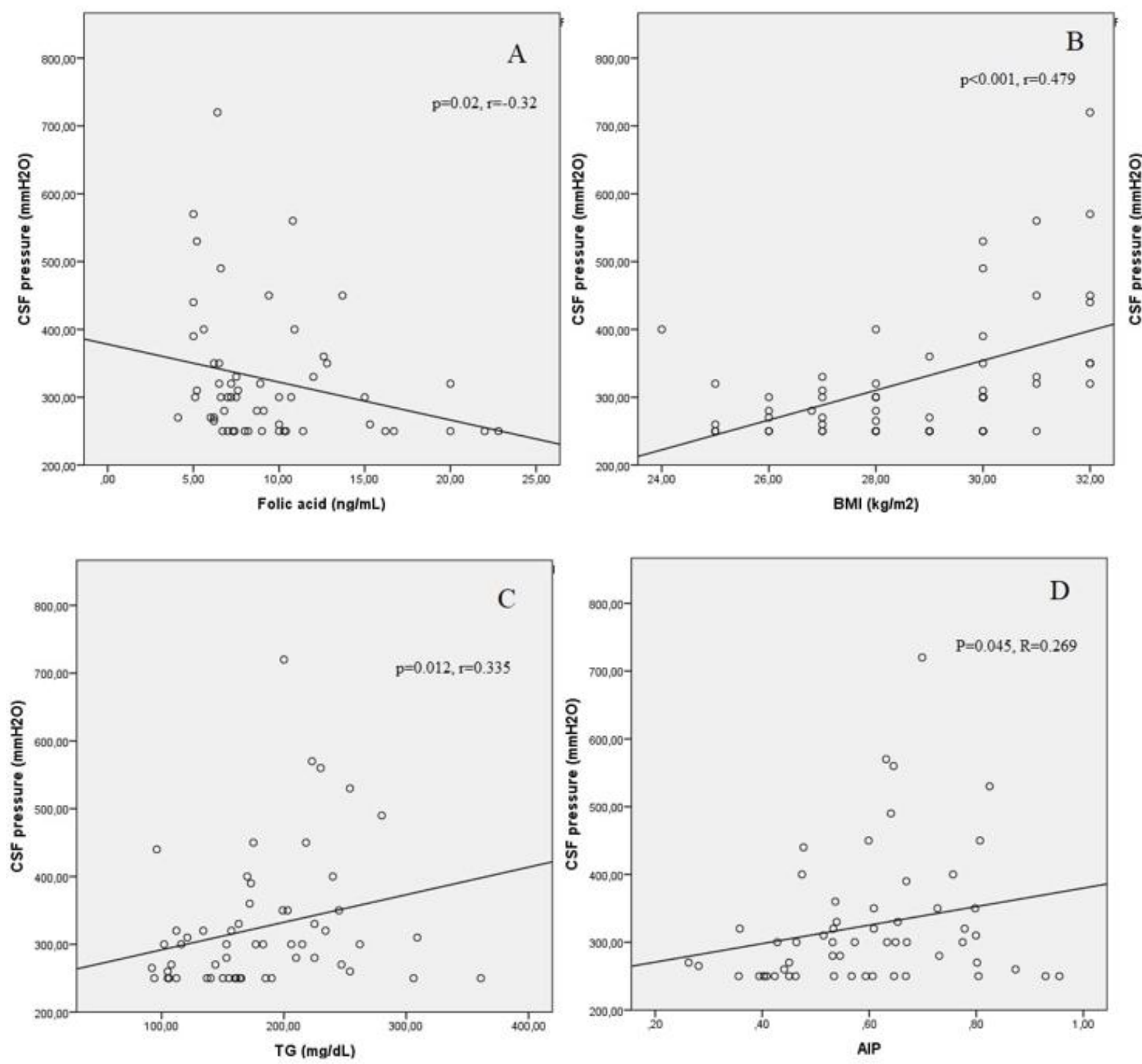

Figure 1: Correlation between cerebrospinal fluid pressure and folic acid level, BMI, TG level, AIP. X axis represents the folic acid level in $\mathrm{ng} / \mathrm{mL}$ (A), BMI in $\mathrm{kg} / \mathrm{m} 2$ (B), TG level in $\mathrm{mg} / \mathrm{dL}$ (C), AIP (D) whereas y-axis represents the cerebrospinal fluid pressure levels in $\mathrm{mmH} 2 \mathrm{O}$. Each point on the graph represents one patient. There was a significant negative correlation between folic acid level and cerebrospinal fluid pressure $(\mathrm{p}=0.02, \mathrm{r}=-0.32)$ and a positive correlation between BMI, TG, AIP and CSF pressure level $(\mathrm{p}<0.001, \mathrm{r}=0.48$; $\mathrm{p}=0.012, \mathrm{r}=0.335 ; \mathrm{p}=0.045, \mathrm{r}=0.27)$.

\section{Patient selection}

Since it was a retrospective study, informed consent was not required from the patients. Patients over 18 years of age with a diagnosis of IIH were evaluated. The diagnoses of the patients were made according to the modified Dandy criteria. Patients with secondary intracranial hypertension due to etiology such as vasculitis, medication, cerebral venous thrombosis, and malignancy were excluded from the study. Lumbar puncture of the patients was performed in the left lateral position and a standard lumbar puncture manometer was used for measurement. CSF pressure of the patients was $25 \mathrm{~cm}$ and above. Demographic data (age, gender), height $(\mathrm{cm})$, weight $(\mathrm{kg})$ data (measured without shoes and with light clothing) to calculate the body mass index (BMI) from the files of the people included in the study, vitamin B12, vitamin D, homocysteine, folic acid, TG, HDL-C levels, CSF pressure, CSF microprotein levels after 12 hours of fasting were recorded. The AIP value was calculated by dividing the TG level logarithmically by HDL-C.
BMI $18.5-24.9 \mathrm{~kg} / \mathrm{m}^{2}$ is considered as normal weight, 25 $29.9 \mathrm{~kg} / \mathrm{m}^{2}$ as overweight, $30-39.9 \mathrm{~kg} / \mathrm{m}^{2}$ as obese, $>40$ $\mathrm{kg} / \mathrm{m}^{2}$ as morbid obese.

\section{Data analysis:}

Statistical analysis was done using SPSS 20 software. Descriptive statistics were used to summarize the data. Data were expressed as mean and standard deviation, median (minimum-maximum), percentage. Normality assumption for continuous variables was analyzed using the Kolmogorov Smirnov test. Spearman correlation coefficients were calculated to investigate the relationship of CSF pressure and AIP with other biochemical parameters. Statistical significance level was accepted as $\mathrm{p}$ $<0.05$.

\section{Results}

Files of 64 patients who were followed up with a diagnosis of pseudotumor cerebri were analyzed. 8 patients with secondary intracranial hypertension were excluded from the 
study, and 56 patients were evaluated. The average age of the patients was $35.96+9.69$ years, 92.9\% $(n=52)$ were female, $7.14 \%(n=4)$ were male. Biochemical data of the study population are given in table 1 , and clinical data of the patients are given in table 2. Of the patients diagnosed with IIH, $55.4 \%(n=31)$ were overweight, $42.9 \%(n=24)$ were obese, $1.8 \%(n=1)$ were with normal weight. There was no significant correlation between vitamin B12, vitamin $\mathrm{D}$, homocysteine, HDL-C and CSF microprotein levels and CSF pressure level in patients with a diagnosis of IIH. There was a negative correlation between folic acid level and CSF pressure level, and a positive correlation between BMI, TG, AIP and CSF pressure level ( $\mathrm{p}=0.02, \mathrm{r}=-$ $0.32 ; \mathrm{p}<0.001, \mathrm{r}=0.48 ; \mathrm{p}=0.012, \mathrm{r}=0.335 ; \mathrm{p}=0.045, \mathrm{r}=0.27)$ (Figure 1). The correlation coefficients between the CSF opening pressure and AIP values and other parameters of patients with a diagnosis of IIH are shown in table 3 .

Table 1. Biochemical data of the study population $(n=56)$

\begin{tabular}{lll}
\hline & mean $_{ \pm}$SD & Median (min-max) \\
\hline AIP & $0.59+0.16$ & - \\
\hline HDL-C $(\mathrm{mg} / \mathrm{dL})$ & $44.48+8.98$ & - \\
\hline BMI & - & $29(24-32)$ \\
\hline Triglycerides $(\mathrm{mg} / \mathrm{dL})$ & $181.71+60.49$ & - \\
\hline Vitamin D $(\mathrm{ng} / \mathrm{mL})$ & - & $8.65(3-32.30)$ \\
\hline Vitamin B12 $(\mathrm{pg} / \mathrm{mL})$ & - & $207.50(59-713)$ \\
\hline $\begin{array}{l}\text { Homocysteine } \\
\text { umol/L) }\end{array}$ & - & $10(2-21.50)$ \\
\hline Folic acid $(\mathrm{ng} / \mathrm{mL})$ & - & $7.80(4.10-22.80)$ \\
\hline $\begin{array}{l}\text { CSF microprotein } \\
(\mathrm{mg} / \mathrm{dL})\end{array}$ & - & $29.50(13-57)$ \\
\hline $\begin{array}{l}\text { CSF pressure } \\
(\mathrm{mmH} 2 \mathrm{O})\end{array}$ & - & $300(250-720)$ \\
\hline N
\end{tabular}

Note: SD: standard deviation, IIH: idiopathic intracranial hypertension, BMI: Body Mass Index, CSF: cerebro spinal fluid, HDL-C: high density lipoprotein cholesterol, min: minimum, max: maximum, AIP: atherogenic index of plasma.

Table 2. Clinical data of IIH patients $(n=56)$

\begin{tabular}{lcc}
\hline Symptom and findings & n & \% \\
\hline Headache & 53 & 94.64 \\
\hline Tension headache & 34 & 60.71 \\
\hline Migraine headache & 19 & 33.93 \\
\hline Bilateral papillary edema & 56 & 100 \\
\hline Tinnitus & 5 & 8.93 \\
\hline Dizziness & 2 & 3.57 \\
\hline Diplopia & 2 & 3.57 \\
\hline Abducens paralysis & 2 & 3.57 \\
\hline Blurred vision & 12 & 21.43 \\
\hline IIH: Idiopathic intracranial hypertension.
\end{tabular}

Table 3. Spearman correlation coefficients with CSF opening pressure and AIP $(n=56)$

\begin{tabular}{lcccc}
\hline & \multicolumn{2}{c}{$\begin{array}{c}\text { CSF opening } \\
\text { ressure }\end{array}$} & \multicolumn{2}{c}{ AIP } \\
\hline & r & $\mathbf{p}$ & $\mathbf{r}$ & $\mathbf{p}$ \\
\hline BMI & 0.48 & $<\mathbf{0 . 0 0 1 *}$ & 0.32 & $\mathbf{0 . 0 2}$ \\
\hline Vitamin D & -0.13 & 0.35 & 0.04 & 0.75 \\
\hline Vitamin B12 & 0.12 & 0.37 & -0.16 & 0.24 \\
\hline Floic acid & -0.32 & $\mathbf{0 . 0 2} *$ & 0.03 & 0.83 \\
\hline Homocysteine & -0.05 & 0.70 & 0.04 & 0.80 \\
\hline TG & 0.012 & $\mathbf{0 . 0 1}$ & 0.84 & $<\mathbf{0 . 0 0 1 *}$ \\
\hline HDL-C & 0.04 & 0.76 & -0.47 & $<\mathbf{0 . 0 0 1 *}$ \\
\hline AIP & 0.269 & $\mathbf{0 . 0 4 5}$ & - & - \\
\hline CSF Microprotein & -0.24 & 0.07 & -0.19 & 0.15 \\
\hline TG:Tiglyceris
\end{tabular}

TG:Triglycerides, HDL-C: high density lipoprotein cholesterol, AIP: Atherogenic index of plasma, CSF: Cerebro Spinal Fluid, $* \mathrm{p}<0.05$

\section{Discussion}

There was a weak and negative correlation between CSF pressure and folic acid level in patients diagnosed with IIH $(\mathrm{p}=0.02, \mathrm{r}=-0.32)$ and a positive correlation between BMI, TG, AIP and CSF pressure level $(\mathrm{p}<0.001, \mathrm{r}=0.48 ; \mathrm{p}=0.012$, $\mathrm{r}=0.335 ; \mathrm{p}=0.045, \mathrm{r}=0.27) .55 .4 \% \quad(\mathrm{n}=31)$ of the patients were overweight, $42.9 \%(n=24)$ were obese, $1.8 \%(n=1)$ were with normal weight.

IIH is mostly seen in overweight women and its etiopathogenesis is not exactly known. In a retrospective study, it has been shown that increased BMI is associated with increased CSF pressure, as in our study. ${ }^{17}$ In a different study, it was shown that there was no correlation between BMI and CSF pressure in patients diagnosed with $\mathrm{IIH}$, but a significant correlation between BMI and CSF pressure in patients with normal intracranial pressure. ${ }^{18}$ This suggests that both obesity and metabolic characteristics of adipose tissue are effective in the emergence of the disease in patients diagnosed with IIH. The absence of IIH in all obese patients indicates metabolic changes in these patients. In some studies, it has been emphasized that regional fat distribution, not BMI, is effective in increasing CSF pressure in IIH patients. ${ }^{19} \mathrm{~A}$ study showed that there is a positive correlation between BMI and body fat percentage and CSF opening pressure in people without a diagnosis of IIH, but there is no relationship between body fat distribution and CSF opening pressure. ${ }^{18}$ These results support that weight loss has an important role in reducing CSF pressure.

Adipose tissue plays a role in the development of pathological conditions such as inflammation, obesity and metabolic syndrome by secreting various hormones and proinflammatory cytokines. ${ }^{20}$ Excessive accumulation of adipose tissue in the abdominal cavity has been associated with a number of metabolic changes, including insulin resistance, hyperinsulinemia, high TG levels, low HDL cholesterol, and hypertension. ${ }^{21}$ After long-term fasting, TGs start to move from the adipose tissue and the amount of free fatty acids and TG in the blood increases. ${ }^{22}$ In an experimental study conducted, it has been shown that TGs cross the blood brain barrier and completely inhibit the ability of leptin to activate the receptor. ${ }^{23}$ While leptin normally creates a feeling of satiety, leptin cannot perform its normal function in case of high TG, and the absence of a feeling of satiety also prepares the ground for the development of obesity. TG and HDL-C serum level are parameters that can be measured easily. In our study where we investigated whether AIP calculated using TG and HDL-C was related to CSF pressure in patients diagnosed with IIH, we found that there was significant relationship between these parameters. The fact that the vast majority of patients diagnosed with $\mathrm{IIH}$ are obese and that the elevation of TG lays the groundwork for the development of obesity brings to mind the question of "Can drugs such as Gemfibrozil that reduce TG level be an effective option in the treatment of IIH patients?"

Folate is one of the water-soluble B vitamins. It plays a role in the formation of blood cells, the formation of deoxyribonucleic acid (DNA) and ribonucleic acid (RNA), and homocysteine metabolism. 
While daily folate intake is sufficient with a healthy diet, a decrease in folate intake with inadequate diet can cause anemia. Cofactors necessary for homocysteine metabolism are vitamins B12, B6 and folate. Insufficient intake of these with food can cause hyperhomocysteinemia. Hyperhomocysteinemia is one of the causes of coagulopathy. In our study, there was a weak correlation between folic acid level and CSF pressure level, which was negatively significant $(\mathrm{p}=0.02, \mathrm{r}=-0.32)$, but there was no relationship between homocysteine level and CSF pressure. The increased homocysteine level due to the low folic acid level may cause the formation of microthrombi and create obstacles in cerebral venous return. This may lead to an even higher CSF pressure in patients with folic acid deficiency. The fact that there is a negative correlation between folic acid level and CSF pressure suggests that adding folic acid to the treatment of these patients may provide additional benefit if the folic acid level is below the normal limit.

\section{Conclusion}

AIP is a parameter that can be used in the follow-up and treatment of patients diagnosed with IIH. IIH is a disease in which medical treatment options are limited, surgery is applied to patients in whom medical treatment does not court, and sometimes morbidity cannot be prevented by surgical treatment. We think that adding folic acid to the treatment in patients with folic acid deficiency may contribute to clinical improvement. Besides, the efficacy of drugs such as gemfibrozil, which lowers TG levels, should be investigated in this patient group, mostly obese patients. Larger studies with large patient groups are needed for an easily accessible biomarker that can be used in the followup of patients diagnosed with IIH and will enable the determination of new treatment strategies.

\section{Conflict of Interest}

The authors have no conflict of interest to disclose.

\section{Acknowledgement}

None.

\section{References}

1. Markey KA, Mollan SP, Jensen RH, Sinclair AJ. Understanding idiopathic intracranial hypertension: mechanisms, management, and future directions. Lancet Neurol; 2016. 15(1):78-91. DOI: 10.1016/S1474-4422(15)00298-7.

2. Szewka AJ, Bruce BB, Newman NJ, Biousse V. Idiopathic intracranial hypertension: Relation Between Obesity and Visual Outcomes. Journal of NeuroOphthalmology; 2013. 33(1):4-8. DOI: $10.1097 /$ WNO.0b013e31823f852d.

3. Durcan FJ, Corbett JJ, Wall M. The incidence of pseudotumor cerebri. Population studies in Iowa and Louisiana. Arch Neurol; 1988. 45(8):875-7.

DOI: 10.1001/archneur.1988.00520320065016.

4. Craig JJ, Mulholland DA, Gibson JM. Idiopathic intracranial hypertension; incidence, presenting features and outcome in Northern Ireland (19911995). Ulster Med J; 2001. 70(1):31-5. Avalaibe from: https://www.ncbi.nlm.nih.gov/pubmed/11428322.

5. Degnan AJ, Levy LM. Pseudotumor cerebri: Brief review of clinical syndrome and imaging findings. AJNR Am J Neuroradiol; 2011. 32(11):1986-93. DOI: 10.3174/ajnr.A2404.

6. Giuseffi V, Wall M, Siegel PZ, Rojas PB. Symptoms and disease associations in idiopathic intracranial hypertension (pseudotumor cerebri): a case-control study. Neurology; 1991. 41(2(Pt 1)):239-44.

DOI: $10.1212 /$ wnl.41.2_part_1.239.

7. Lueck C, McIlwaine G. Interventions for idiopathic intracranial hypertension. Cochrane Database Syst Rev. 2005(3):CD003434.

DOI: 10.1002/14651858.CD003434.pub2.

8. Walker R. Idiopathic intracranial hypertension: any light on the mechanism of the raised pressure? : BMJ Publishing Group Ltd; 2001.

DOI: 10.1136/jnnp.71.1.1

9. Bays HE, Toth PP, Kris-Etherton PM, Abate N, Aronne LJ, Brown WV, et al. Obesity, adiposity, and dyslipidemia: a consensus statement from the National Lipid Association. J Clin Lipidol; 2013. 7(4):304-83. DOI: 10.1016/j.jacl.2013.04.001.

10. Nishide R, Ando M, Funabashi H, Yoda Y, Nakano M, Shima M. Association of serum hs-CRP and lipids with obesity in school children in a 12-month followup study in Japan. Environ Health Prev Med; 2015. 20(2):116-22. DOI: 10.1007/s12199-014-0433-3.

11. Skinner AC, Perrin EM, Moss LA, Skelton JA. Cardiometabolic Risks and Severity of Obesity in Children and Young Adults. N Engl J Med; 2015. 373(14):1307-17. DOI: 10.1056/NEJMoa1502821.

12. Dobiášová $\mathrm{M}$, Frohlich J. The plasma parameter log (TG/HDL-C) as an atherogenic index: Correlation with lipoprotein particle size and esterification rate in apob-lipoprotein-depleted plasma (FER HDL). Clinical biochemistry; 2001. 34(7):583-8.

DOI: $10.1016 / \mathrm{s} 0009-9120(01) 00263-6$

13. Bora K, Pathak M, Borah P, Hussain MI, Das D. Association of the apolipoprotein AI gene polymorphisms with cardiovascular disease risk factors and atherogenic indices in patients from Assam, Northeast India. Balkan Journal of Medical Genetics; 2017. 20(1):59-70. DOI: 10.1515/bjmg2017-0002

14. Yang SH, Du Y, Li XL, Zhang Y, Li S, Xu RX, et al. Triglyceride to high-density lipoprotein cholesterol ratio and cardiovascular events in diabetics with coronary artery disease. Am J Med Sci; 2017. 354(2):117-24. DOI: 10.1016/j.amjms.2017.03.032.

15. Cai GJ, Shi GW, Xue SL, Lu W. The atherogenic index of plasma is a strong and independent predictor for coronary artery disease in the Chinese Han population. Medicine; 2017. 96(37). DOI: 10.1097/MD.0000000000008058.

16. Zhu XW, Yu LG, Zhou H, Ma QH, Zhou XH, Lei T, et al. Atherogenic index of plasma is a novel and better biomarker associated with obesity: a population-based cross-sectional study in China. Lipids in Health and Disease; 2018. 17(1):1-6. DOI: 10.1186/s12944-018-0686-8. 
17. Berdahl JP, Fleischman D, Zaydlarova J, Stinnett S, Allingham RR, Fautsch MP. Body mass index has a linear relationship with cerebrospinal fluid pressure. Investigative Ophthalmology \& Visual Science; 2012. 53(3):1422-7. DOI: 10.1167/iovs.11-8220.

18. Wakerley BR, Warner R, Cole M, Stone K, Foy C, Sittampalam M. Cerebrospinal fluid opening pressure: The effect of body mass index and body composition. Clin Neurol Neurosurg; 2020. 188:105597. DOI: 10.1016/j.clineuro.2019.105597.

19. Sugerman HJ, DeMaria EJ, Felton WL, 3rd, Nakatsuka M, Sismanis A. Increased intra-abdominal pressure and cardiac filling pressures in obesityassociated pseudotumor cerebri. Neurology; 1997. 49(2):507-11. DOI: 10.1212/wnl.49.2.507.

20. Ahbab S, Yenigün M. Yağ Dokusu Hormonlar1; Genel Bir Bakış. Haseki Tıp Bülteni; 2011. 49:96-8. Avalaible from: https://cms.galenos.com.tr/Uploads/Article_6120/9698.pdf
21. Detection NCEP EPo, Adults To HBCi. Third report of the National Cholesterol Education Program (NCEP) Expert Panel on detection, evaluation, and treatment of high blood cholesterol in adults (Adult Treatment Panel III): National Cholesterol Education Program, National Heart, Lung, and Blood; 2002. Avalaible from: https://pubmed.ncbi.nlm.nih.gov/12485966/

22. Guiducci L, Jarvisalo M, Kiss J, Nagren K, Viljanen A, Naum AG, et al. [11C] palmitate kinetics across the splanchnic bed in arterial, portal and hepatic venous plasma during fasting and euglycemic hyperinsulinemia. Nucl Med Biol; 2006. 33(4):521-8. DOI: 10.1016/j.nucmedbio.2006.02.003.

23. Banks WA, Farr SA, Salameh TS, Niehoff ML, Rhea EM, Morley JE, et al. Triglycerides cross the bloodbrain barrier and induce central leptin and insulin receptor resistance. Int J Obes (Lond); 2018. 42(3):391-7. DOI: 10.1038/ijo.2017.231. 